\title{
DISCURSOS DA SUSTENTABILIDADE URBANA
}

\author{
HENRI ACSELRAD
}

R E S U M O A noção de sustentabilidade remete antes à lógica das práticas, em que efeitos práticos considerados desejáveis são levados a acontecer, do que ao campo do conhecimento cientifico, em que os conceitos são construidos para explicar o real. Aplicada ao espaço urbano, a noção de sustentabilidade tem acionado diversas representações para a gestão das cidades, desde a administração de riscos e incertezas ao incremento da "resiliência" - a capacidade adaptativa - das estruturas urbanas. O que parece organizar analiticamente o discurso da "sustentabilidade urbana" seria sua distribuição em dois campos: de um lado, aquele que privilegia uma representação técnica das cidades pela articulação da noção de sustentabilidade urbana aos "modos de gestão dos fluxos de energia e materiais associados ao crescimento urbano"; de outro, aquele que define a insustentabilidade das cidades pela queda da produtividade dos investimentos urbanos, ou seja, pela "incapacidade destes últimos acompanharem o ritmo de crescimento das demandas sociais", o que coloca em jogo, conseqüentemente, o espaço urbano como território político. ${ }^{*}$

PALAVRAS-CHAVE Sustentabilidade; planejamento urbano; politica ambiental.

\footnotetext{
* Trabalho selecionado da sessão temática 5 - "Desenvolvimento urbano sustentável: que qualidade e para quem?"
}

\section{INTRODUÇÃO}

Diversas matrizes discursivas têm sido associadas à noção de sustentabilidade desde que o Relatório Brundtland a lançou no debate público internacional em 1987. Entre elas, podem-se destacar a matriz da eficiência, que pretende combater o desperdício da base material do desenvolvimento, estendendo a racionalidade econômica ao "espaço nãomercantil planetário"; da escala, que propugna um limite quantitativo ao crescimento econômico e à pressão que ele exerce sobre os "recursos ambientais"; da eqüidade, que articula analiticamente princípios de justiça e ecologia; da autosuficiência, que prega a desvinculação de economias nacionais e sociedades tradicionais dos fluxos do mercado mundial como estratégia apropriada a assegurar a capacidade de auto-regulação comunitária das condiçōes de reprodução da base material do desenvolvimento; da ética, que inscreve a apropriação social do mundo material em um debate sobre os valores de Bem e de Mal, evidenciando as interaçôes da base material do desenvolvimento com as condições de continuidade da vida no planeta.

Desde a United Nations Conference on Environment and Development - Unced (1992), a noção de sustentabilidade vem ocupando espaço crescente nos debates sobre desenvolvimento. De um lado, no interior do discurso desenvolvimentista - produzido por agências multilaterais, consultores técnicos e ideólogos do desenvolvimento -, verificouse um investimento na correção de rumos, no esverdeamento dos projetos, na readequa- 
ção dos processos decisórios. Com ajustes - acreditam estes atores - a proposta do desenvolvimento poderia ser resgatada, suas dimensões autofágicas, superadas, sua durabilidade, assegurada, sua vigência, sustentada. Por outro lado, no campo das ONGs, em meio à crítica dos limites do conteúdo que governos e instituiçôes oficiais vêm atribuindo ao desenvolvimento, que pretendem, sustentável, alguns vêem na sustentabilidade uma nova crença destinada a substituir a idéia de progresso, constituir "um novo princípio organizador de um desenvolvimento centrado no povo", e ser capaz de "tornar-se a visão mobilizadora da sociedade civil e o princípio guia da transformação das instituições da sociedade dominante" (PCDF, 1992).

O que prevalece são, porém, expressões interrogativas recorrentes, nas quais a sustentabilidade é vista como "um princípio em evolução", "um conceito infinito", "que poucos sabem o que é" e "que requer muita pesquisa adicional", manifestaçôes de um positivismo frustrado: o desenvolvimento sustentável seria um dado objetivo que, no entanto, não se conseguiu ainda apreender. Mas, como definir algo que não existe? E que, ao existir, será, sem dúvida, uma construção social? E que, como tal, poderá também compreender diferentes conteúdos e práticas a reivindicar seu nome. Isto nos esclarece por que distintas representaçôes e valores vêm sendo associados à noção de sustentabilidade: são discursos em disputa pela expressão mais legítima. Pois a sustentabilidade é uma noção a que se pode recorrer para tornar objetivas diferentes representaçôes e idéias.

A suposta imprecisão do conceito de sustentabilidade sugere que não há ainda hegemonia estabelecida entre os diferentes discursos. Os ecólogos parecem mal posicionados para a disputa em um terreno enraizado pelos valores do produtivismo fordista e do progresso material. A visão sociopolítica tem se restringido ao esforço de ONGs, mais especificamente na atribuição de precedência ao discurso da eqüidade, com ênfase ao âmbito das relações internacionais. O discurso econômico foi o que, sem dúvida, melhor se apropriou da noção até aqui, até mesmo por considerar sua preexistência na teoria do capital e da renda de Hicks.

Mas, ao contrário dos conceitos analíticos voltados para a explicação do real, a noção de sustentabilidade está submetida à lógica das práticas: articula-se a efeitos sociais desejados, a funções práticas que o discurso pretende tornar realidade objetiva. Tal consideração nos remete a processos de legitimação/deslegitimação de práticas e atores sociais. Por um lado, se a sustentabilidade é vista como algo bom, desejável, consensual, a definição que prevalecer vai construir autoridade para que se discriminem, em seu nome, as boas práticas das ruins. Abre-se, portanto, uma luta simbólica pelo reconhecimento da autoridade para falar em sustentabilidade. E para isso faz-se necessário constituir uma audiência apropriada, um campo de interlocução eficiente onde se possa encontrar aprovação. Poder-se-á falar, assim, em nome dos (e para os) que querem a sobrevivência do planeta, das comunidades sustentáveis, da diversidade cultural etc. Em síntese: a luta em torno a tal representação exprime a disputa entre diferentes práticas e formas sociais que se pretendem compatíveis ou portadoras da sustentabilidade.

Para se afirmar, porém, que algo - uma coisa ou uma prática social - é sustentável, será preciso recorrer a uma comparação de atributos entre dois momentos situados no tempo: entre passado e presente, entre presente e futuro. Como a comparação passadopresente, no horizonte do atual modelo de desenvolvimento, é expressiva do que se pretende insustentável, parte-se para a comparação presente-futuro. Dir-se-ão então sustentáveis as práticas que se pretendam compatíveis com a qualidade futura postulada como desejável. E esta relação entre um presente conhecido e um futuro desconhecido e dese- 
jável coloca a noção de sustentabilidade no campo do que alguns chamam de "causalidade teleológica" - "que tem, como causa suficiente de um comportamento, um acontecimento que contém em sua descrição a exigência de que um outro acontecimento, chamado seu fim, aconteça" (Costa, 1994). Ou seja, a causa é definida pelo fim; a ordem de seqüência dos acontecimentos está embutida na condição antecedente definida como causa. É sustentável hoje aquele conjunto de práticas portadoras da sustentabilidade no futuro.

O recurso a esta "causalidade teleológica" é particularmente questionável quando ela implica reconstruir o presente à luz de supostas exigências do futuro. ${ }^{1} \mathrm{~A}$ experiência histórica registra exemplos no mínimo discutíveis desta atualização política do futuro: "é preciso crescer para depois distribuir", "estabilizar a economia para depois crescer", "sacrificar o presente para conquistar o futuro" etc. Os riscos são tanto maiores quanto se sabe que os que ocupam posições dominantes no espaço social também estão em posições dominantes no campo da produção das representaçôes e idéias. Se o Estado e o empresariado - forças hegemônicas no projeto desenvolvimentista - incorporam a crítica à insustentabilidade do modelo de desenvolvimento, passam a ocupar também posição privilegiada para dar conteúdo à própria noção de sustentabilidade.

Mas isto não quer dizer que a questão esteja resolvida de uma vez por todas. Ao contrário, autoridade e legitimidade, atributos decisivos para todos os atores que disputam o poder de definir o que é sustentável, também dependem da maneira como estes atores elaboram seus discursos alternativos sobre a questão, e da força relativa que acumulam no campo das idéias. No presente trabalho faremos um mapeamento das principais matrizes discursivas da sustentabilidade urbana, procurando identificar as inflexões que os atores sociais, que recorrem a esta noção, apontam para as práticas sociais de construção do espaço das cidades, pois o futuro das cidades dependerá em grande parte dos conceitos constituintes do projeto de futuro construído pelos agentes relevantes na produção do espaço urbano.

\section{SUSTENTABILIDADE E CIDADE}

A associação da noção de sustentabilidade ao debate sobre desenvolvimento das cidades tem origem nas rearticulaçôes políticas pelas quais um certo número de atores envolvidos na produção do espaço urbano procuram dar legitimidade a suas perspectivas, evidenciando a compatibilidade delas com os propósitos de dar durabilidade ao desenvolvimento, de acordo com os princípios da Agenda 21, resultante da Conferência da ONU sobre Desenvolvimento e Meio Ambiente. ${ }^{2}$ Ao mesmo tempo que verificamos uma "ambientalização" do debate sobre políticas urbanas, observamos, também, um movimento em sentido oposto, com a entrada crescente do discurso ambiental no tratamento das questôes urbanas, seja por iniciativa de atores sociais da cidade que incorporam a temática do meio ambiente, sob o argumento da substancial concentração populacional nas metrópoles, seja pela própria trajetória de urbanização crescente da carteira ambiental dos projetos do Banco Mundial.

Não podemos deixar de associar também o recurso à noção de sustentabilidade urbana a estratégias de implementação da metáfora cidade-empresa que projetam na "cidade sustentável" alguns dos supostos atributos de atratividade de investimentos, no contexto da competição gobal. Conduzir as cidades para um futuro sustentável significa neste caso "promover a produtividade no uso dos recursos ambientais e fortalecer as vantagens
1 Na causalidade teleológica, "o que não existe ainda pode agir sobre o que é"; cf. Soubeyron, O., "La mer du Sahara", in L'Aventure Humaine, Paris, n.1, p.27, janvier 1995.
2 Várias redes internacionais de municipalidades, notadamente européias, foram articuladas, a partir de 1992, com o fim de pôr em prática os preceitos globais do desenvolvimento sustentável sob a forma de orientações práticas e tangíveis; cf. Emelianoff, C., "Les Villes Durables, l'émergence de nouvelles temporalités dans des vieux espaces urbains", in Ecologie Politique, n.13, p.38, printemps 1995. 
competitivas" (Durazo, 1997, p.51). Com maior ou menos vinculaçãa às perspectivas de planejamento "empresarial" das cidades, a noção de sustentabilidade oferecerá a oportunidade para a legitimação de uma "ecocracia" emergente, favorecida em particular pela criação de novas instâncias governativas e regulatórias voltadas para o tratamento da questão ambiental, em geral, e ambiental urbana, em particular.

No debate contemporâneo, econtraremos várias articulações lógicas entre a reprodução das estruturas urbanas e sua base especificamente material. Encontraremos, em particular, três representaçôes basicamente distintas da cidade, às quais corresponderão também diferentes sentidos do que se pretende legitimamente capaz de dar durabilidade à integridade do urbano.

\section{A RepresentaÇÃo TECNO-MATERIAL DAS CidADES}

Uma primeira articulação associa a transição para a sustentabilidade urbana à repro-

3 Pillet \& Odum assim enunciam as bases eco-energéticas de uma macroeconomia ambiental: "O meio ambiente pode ser visto, pouco a pouco, como um quase-setor da economia ... e as externalidades ambientais podem ser definidas como consequências permanentes da extração, do tratamento, do consumo e da descarga de matéria e energia. A lei de conservação da matéria e da energia exige que o conjunto dos rejeitos lançado pela economia no meio ambiente seja igual à soma de todos os recursos extraídos do mesmo através das atividades econômicas", cf. Pillet, G., Odum, H. T., Énergie, Écologie, Économie, Genebra, 1987, p.178-9.

4 "A cidade torna-se o lugar onde se concentram os problemas ambientais e sociais da nação", cf. Beaucire, F., "La Ville Éclatée", in Passet, R., Theys, J., Héritiers du Futur - Aménagement du Territoire, Environnement et Développement Durable, Paris: L'Aube, s.d., p.187. "Não é impossível pensar-se que o encontro da ecologia com a cidade possa concorrer para a requalificação de um sentido do urbano, de forma e identidade originais, e subtrair a cidade da entropia que a ronda, conferindoIhe um dinamismo mais positivo", cf. Lévy, J. C., "Les Étapes de la Métropolisation", in Passet, R., Theys, J., op. cit., p.189. dução adaptativa das estruturas urbanas com foco no ajustamento das bases técnicas das cidades, com base em modelos de "racionalidade ecoenergética" bano”. Em ambos os casos, a cidade será vista em sua continuidade material de estoques e fluxos.

$\mathrm{Na}$ perspectiva da eficiência especificamente material, a cidade sustentável será aquela que, para uma mesma oferta de serviços, minimiza o consumo de energia fóssil e de outros recursos materiais, explorando ao máximo os fluxos locais e satisfazendo o critério de conservação de estoques e de redução do volume de rejeitos. Vigora aqui uma representação técnico-material da cidade como uma matriz composta por um vetor de consumo de espaço, energia e matérias-primas e um vetor de produção de rejeitos (Déléage, 1995, p.35). A leitura da cidade como um sistema termodinâmico aberto identificará no urbano o locus privilegiado da produção crescente de entropia, emblema da irreprodutibilidade ilimitada do processo de crescimento econômico-material. ${ }^{4} \mathrm{~A}$ insustentabilidade urbana é, nesta perspectiva, uma expressão social da irreversibilidade termodinâmica. Com base em uma leitura da cidade como lugar por excelência da perda de capacidade de transformação de energia em trabalho, caberia ao planejamento urbano minimizar a degradação energética e desacelerar a trajetória da irreversibilidade. Tal representação das cidades aponta para novos modelos técnicos do urbano, fundados na racionalidade econômica aplicada aos fluxos de matéria-energia. Para se reduzir o impacto entrópico das práticas urbanas, caberia assim adotar tecnologias poupadoras de espaço, matéria e energia, e voltadas para a reciclagem de materiais. A idéia de eficiência ecoenergética pretende conseqüentemente estender o campo de vigência da racionalidade econômica.

A ineficiência ecoenergética pode ser traduzida também em termos de distribuição espacial inadequada à economia de meios, ou seja, como o resultado de uma imprópria distribuição locacional das populações e atividades no espaço urbano. A insustentabilidade decorreria assim das "crescentes assimetrias entre a localização espacial dos recursos e da população, das pressões excessivas sobre o meio físico circundante e sobre os sistemas ecológicos regionais" (Durazo, 1997, p.51). A sustentabilidade decorreria, neste caso, da redistribuição espacial da pressão técnica de populaçōes e atividades sobre a base de recursos ambientais urbanos. A problemática malthusiana é aqui inscrita no quadro urbano, introduzindo a "hipótese do limite da capacidade urbana" e concentrando o foco nas estratégias de descentralização, a saber, na distribuição de funçōes das metrópoles para as 
regiōes, das áreas metropolitanas internas para as áreas metropolitanas periféricas, do centro para os subcentros das cidades. ${ }^{5}$

A concepção da sustentabilidade como trajetória progressiva em rumo à eficiência ecoenergética é normalmente acompanhada da constituição de uma base social de apoio a projetos de mudança técnica urbana, pela via da "educação ambiental", da disseminação de uma "consciência ecológica", de projetos comunitários de reciclagem ou pelo engendramento de uma "economia da reciclagem". A recusa do antagonismo entre o meio ambiente e a economia fará também da busca da sustentabilidade urbana a ocasião de fazer valer a potência simbólica do mercado como instância de regulação das cidades. Pois se o futuro é, no pensamento hegemônico, o da plena vigência das instituiçôes mercantis, dirigir as cidades para um futuro sustentável significa promover a produtividade urbana e fortalecer as vantagens competitivas.

Etratégias argumentativas de ordem global serão, com freqüência, acionadas para promover inovaçôes na matriz técnica das cidades, ${ }^{6}$ seja com a introdução de tecnologias urbanas poupadoras de recursos, seja com a redistribuição espacial de populações e atividades: o que é bom para o planeta é considerado bom para a cidade. A convergência entre sustentabilidade urbana local e sustentabilidade global é vista geralmente como um simplificador político, posto que no plano local os responsáveis pela poluição e as autoridade políticas são claramente identificáveis.

Um contradiscurso opõe, no entanto, sustentabilidade global e sustentabilidade local urbana - o que é bom para o planeta não seria o melhor para a cidade. Por um lado, as economias de escala de transporte, iluminação e calefação nas cidades concentradas reduzem o consumo per capita de energia, favorecendo as estratégias de sustentabilidade global. Por outro, se a capacidade de regeneração dos ecossistemas é constante por unidade de extensão territorial, as cidades concentradas sofrem efeitos indesejáveis com a elevação da densidade territorial da produção de rejeitos, compromentendo a sustentabilidade em nível local. Neste caso, a busca de ecoeficiência seria motivada por razóes atinentes ao próprio "urbano" e não por razões de ordem planetária. Em ambos estes casos, no entanto, com convergência ou divergência entre sustentabilidade urbana e global, a ecoeficiência será legitimada como eixo das estratégias de ação, e o mercado será considerado seu melhor instrumento.

A idéia de insustentabilidade energética das cidades não é restrita às grandes metrópoles com alta concentração demográfica, mas também estende-se à cidade "fragmentada" e "desdensificada" da "sociedade imaterial": "a desdensificação dos homens e a fragmentação policêntrica das atividades", afırma Beaucire, "são dispendiosas em recursos materiais e produtoras de poluição e efeitos nocivos" (cf. Beaucire, "La Ville Éclatée", in Passet \& Theys, s.d., p.191). Em acréscimo, "a cidade fragmentada e desdensificada é vista como geradora de consumo energético e de custos de reordenamento de redes técnicas (água, eletricidade, telefonia) e de serviços públicos muito elevados" (idem, p.192).

Mas o ajustamento das bases tecno-materiais da cidade pode fundar-se alternativamente em modelos de metabolismo urbano, com uma representação ecossistêmica das cidades, composta por movimentos interativos de circulação, troca e transformação de recursos em trânsito. $\mathrm{O}$ discurso sobre a sustentabilidade das cidades organiza-se, neste caso, pelo recurso à metáfora biológica da "resiliência", que procura descrever a capacidade adaptativa dos "ecossistemas urbanos" para superarem a sua condição de vulnerabilidade ante a choques externos (Godard, 1996, p.33). Neste tipo de representação, a insus-

5 Cf. Omishi, T., "A Capacity Approach for Sustainable Urban Development: an Empirical Study", in Regional Studies, v.28.1, p.39-51. Tal abordagem será questionada por aqueles que entendem a cidade como "instrumento da liberação das atividades humanas com relação à dependência dos recursos locais". Associar a sustentabilidade ao respeito à "capacidade de suporte local" é constranger o debate a um quadro teórico muito limitado, cf. Camagni, R. "Pour Une Ville Durable", in Camagni, R., Gibelli, M. C., Développement Urbain Durable - Quatre Métropoles Européennes, Paris: DATAR/ L'Aube, 1997, p.9.

6 "A argumentação ecológica contribui para ligar a ação mais imediata ao futuro de mais longo prazo de todo o planeta. As mudanças de escala operadas através do esquema das conseqüências generalizadas não são apenas espaciais mas também temporais: toda ação engaja o futuro, tanto o nosso como 0 das gerações futuras. A argumentação ecológica permite assim um movimento constante de ida e vinda entre o passado, o presente e o futuro", in Lafaye, C., Thévenot, L., "Une Justification Écologique? - Conflits dans l'Aménagement de la Nature", Revue Française de Sociologie, XXXIV, p.504, 1993. Na mesma direção Emalionoff afirma que "as cidades sustentáveis constroem pontes e passagens que levam do local ao global e nos convidam a compreender esta nova arquitetura", in "Les Villes Durables, l'émergence de nouvelles temporalités", Ecologie Politique, n.13, p.39, printemps 1995. 
7 Cf. Fabiani, J. L., "Science des Écosystèmes et Protection de la Nature", in Cadoret, A. (Ed.), Protection de La Nature: Histoire et Idéologie, Paris: Ed. L'Harmattan, 1985, p.87-8.

8 Cf. Mitlin, D., Satterthwaite, D., "Sustainable Development and Cities", in Pough, C. (Ed.), Sustainability, the Environment and Urbanization, London: Earthscan, 1996, p.41.

9 Cf. Pough, C., "Introduction", in Pough, C. (Ed.), op. cit., 1996, p.35.

10 "Nós vimos que o poder, nestes tempos modernos, provoca mais conflitos do que os que controla, e sozinho não pode salvar o meio ambiente. É preciso que um movimento ascético espontâneo se oponha ao desenvolvimento econômico. Devemos encontrar uma espécie de estrutura constitucional que, sistematicamente, contraponha-se ao desenvolvimento industrial, reportando cada decisão à pureza do meio ambiente, comportamento que obtém sua legitimidade de um engajamento resolutamente ascético do povo", cf. Douglas, M., "A quelles conditions un ascétisme environnementaliste peut-il réussir?", in Bourg, D. (Ed.), La Nature en Politique ou l'enjeu philosophique de l'ecologie, Paris: L'Harmattan, 1993, p.117-8.

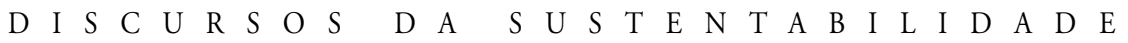

tentabilidade expressaria a incapacidade de reprodução adaptativa das estruturas urbanas diante de rupturas nas condiçōes materiais requeridas para tal reprodução.

A idéia de metabolismo urbano aponta para um modelo de equilíbrio a ser obtido pelo ajustamento apropriado dos fluxos e estoques de matéria e energia. As estratégias de inscrição do desenvolvimento urbano nos quadros científicos de um saber objetivo sobre fluxos e supostos equilíbrios tendem a materializar-se em um conjunto de normas técnicas. Consideradas, porém, as incertezas prevalecentes no saber sobre processos interativos de tal forma complexos em sua espaço-temporalidade, sob cada conjunto de normas de "equilíbrio" estarão implícitos elementos de valores, preferências e "convenções" que, legitimados pela ciência, estarão lançando as bases políticas da coordenação de antecipações e estabilização de cenários de ação (idem, p.32).

Processos de "reestruturaçãoo ecourbana" poder-se-ão inscrever assim nos mecanismos de "cientificização da política", pelos quais os experts da Ecologia Científica estendem seu campo de ação à gestão dos ecossistemas e à produção dos "fundamentos racionais da organização do território". A cientificização do debate sobre o "equilíbrio ecológico" suposto tem por resultado a constituição da necessidade política de uma gestão erudita do território, refletindo o fato de que novos modos institucionalizados de produção do saber são induzidos pela intensificaçãoo da relação entre as burocracias públicas e os representantes do saber ecológico.

Certos autores recusar-se-ão, porém, a pensar a sustentabilidade urbana como processo espacialmente circunscrito, que pressupõe a irrelevância dos fluxos materiais que ligam as cidades aos espaços não-urbanos. Considerando-se a cidade como consumidora de recursos naturais e de espaço para a deposição de rejeitos, bem como a complexidade dos laços urbanos-rurais, afırmar-se-á que "o desenvolvimento urbano sustentável e o desenvolvimento rural sustentável não podem ser separados" ${ }^{8}$ Alguns chegarão mesmo a negar a possibilidade de conceber "cidades sustentáveis", considerando irrealista a pretensão de se restringir o raio de abrangência dos fluxos de matéria e energia requeridos pelo desenvolvimento urbano ao espaço circunscrito das cidades. ${ }^{9}$

\section{A Cidade como EspaÇO da "Qualidade De Vida”}

Uma nova matriz técnica das cidades é também pensada por razões de "qualidade de vida" - componentes não mercantis da existência cotidiana e cidadã da população urbana, notadamente no que se refere às implicaçôes sanitárias das práticas urbanas. Modelos de ascetismo e pureza ${ }^{10}$ são evocados para questionar as bases técnicas do urbano - o urbano crescentemente impregnaria os habitantes das cidades com substâncias nocivas e tóxicas por sua artificialidade. As implicações sanitárias podem, alternativamente, ser associadas a representaçôes coletivas da cidadania, em que as emissóes líquidas e gasosas resultantes das tecnologias urbanas são entendidas como imposição de consumo forçado de produtos invendáveis das atividades da produção mercantil ou do modo de consumo das mercadorias, notadamente dos veículos automotores.

Tal representação da cidadania urbana tende a espraiar-se para o conjunto das políticas urbanas, justificando estruturas que favorecem o desenvolvimento do diálogo e da negociação, bem como a realização de pactos de atribuição de sentido à duração das cidades, não só em sua materialidade, mas como institucionalidade sociopolítica (Emelionoff, 1995, p.48-9).

Uma noção de sustentabilidade associada à categoria patrimônio refere-se não só à materialidade das cidades, mas a seu caráter e suas identidades, a valores e heranças construí- 
dos ao longo do tempo. A perspectiva de fazer durar a existência simbólica de sítios construídos ou sítios naturais "significados", eventualmente "naturalizados", pode inscrever-se tanto em estratégias de fortalecimento do sentimento de pertencimento dos habitantes a suas cidades, como de promoção de uma imagem que marque a cidade por seu patrimônio biofísico, estético ou cultural, em sentido amplo, de modo a atrair capitais na competição global (idem, p.46-7), realizando aquilo que alguns descrevem como um processo de promoção da "economia da beleza em nome da beleza da economia" (Costa, 1997).

A noção de sutentabilidade urbana pode também articular as estratégias argumentativas da eficiência ecoenergética e da qualidade de vida na consideração da forma urbana como "fator determinante da sustentabilidade" (Breheny \& Rookwood, 1996, p.151). A noção de "cidade compacta" reuniria, na perspectiva de documentos da Comissão das Comunidades Européias, por exemplo, os atributos de "alta densidade e uso misto, tendendo a apresentar superior eficiência energética por reduzir as distâncias dos trajetos, maximizar a oferta de transporte público e prover qualidade de vida superior aos residentes" (idem, p.155). A metáfora da cidade compacta teria como configuração formal tendencialmente mais aceita a do modelo policêntrico em rede, com diversificação de funções dos subcentros bem servidos em transportes públicos (Camagni \& Gibelli, 1997, p.33). Sua capacidade de conjugar a eficiência no uso dos recursos ambientais e a qualidade da vida urbana não é porém consensual. Alguns argüirão, ao contrário, que eficiência energética e qualidade de vida são atributos das cidades pouco densas e descentralizadas, por recorrerem a fontes locais de energia e de produção de alimentos em solos rurais disponíveis. ${ }^{11}$

Em ambos os casos, recorrer-se-á ao argumento de que a forma sustentável deverá mesclar, ainda que em escalas distintas, zonas de trabalho, moradia e lazer, reduzindo distâncias e "pedestrizando" as cidades, de modo a frear a mobilidade da energia, das pessoas e bens. Eficiência ecoenergética e qualidade de vida resultariam, nesta perspectiva, da emergência de formas urbanas capazes de expressar a existência desejavelmente crescente de cidades autosuficientes. $\mathrm{O}$ argumento da forma urbana articula-se assim com a idéia da auto-suficiência urbana. No caso da sustentabilidade do desenvolvimento em geral, o argumento da autosuficiência remete a uma crítica do livre mercado e da globalização; no caso da autosuficiência urbana, trata-se de, em nome do combate ao efeito estufa e aos processos entrópicos, orientar-se para maior autonomia energética e econômica das localidades. ${ }^{12}$ Uma recusa da globalização das cidades justificar-se-á assim, do ponto de vista das externalidades negativas e deseconomias energéticas implícitas, na intensificação dos fluxos, própria das chamadas "cidades globais".

\section{A Cidade como Espaço de LegitimaçÃo das Políticas Urbanas}

Sendo a materialidade das cidades politicamente construída, as modalidades de sua reprodução são vistas também como dependentes das condições que legitimam seus pressupostos políticos. A idéia de sustentabilidade é, assim, aplicada às condições de reprodução da legitimidade das políticas urbanas. Fala-se da viabilidade política do crescimento urbano, ou seja, das condições de construção política da base material das cidades. A insustentabilidade exprime, assim, a incapacidade das políticas urbanas adaptarem a oferta de serviços urbanos à quantidade e qualidade das demandas sociais, provocando um "desequilíbrio entre necessidades quotidianas da população e os meios de as satisfazer, entre a demanda por serviços urbanos e os investimentos em redes e infra-estrutura" (Godard, 1996, p.31).
11 Cf. Robertson, J., "Alternatives Futures for Cities", in Cadman, D., Payne, G. (Eds.), The Living City: Towards a Sustainable Future, apud Blowers, A. (Ed.), Planning for a Sustainable Environment, Londres: Earthscan, 1996, p.155.

12 Os autores que rejeitam a noção de "cidades sustentáveis", preferindo articular as cidades no projeto mais amplo de atribuição de sus tentabilidade ao desenvolvimento, consideram, por sua vez, "irrealista esperar que as grandes cidades sejam abastecidas com recursos produzidos em seu entorno imediato"; cf. Pough, C., "Introduction", in Pough, C., op.cit., 1996, p.35. 
13 A articulação da sustentabilidade urbana em princípios de eqüidade pode situar-se em esferas locais ou expandir-se para o plano internacional. "Em suma, o desenvolvimento urbano sustentável liga-se à questão da igualdade econômica e à da desigual divisão internacional do trabalho"; cf. Angotti, T., "Latin American Urbanization and Planning - Inequality and Unsustainability in North and South", in Latin American Perspectives, issue 91, v.23, p.21, fall 1996 .
Acredita-se que quando o crescimento urbano não é acompanhado por investimentos em infra-estrutura, a oferta de serviços urbanos não acompanha o crescimento da demanda. A falta de investimentos na manutenção dos equipamentos urbanos virá, por sua vez, acentuar o déficit na oferta de serviços, o que se rebaterá espacialmente sob a forma de segmentação socioterritorial entre populações atendidas e não-atendidas por tais serviços. ${ }^{13}$ Este processo exprime-se sob a forma de uma "queda da produtividade política dos investimentos urbanos", incrementando os graus de conflito e incerteza no processo de reprodução das estruturas urbanas. A base técnico-material da cidade é vista então como socialmente construída, no interior dos limites de elasticidade das técnicas e das vontades políticas.

A insustentabilidade estaria, portanto, designando um processo de instabilização das bases de legitimidade dos responsáveis pelas políticas urbanas, aos quais se pode reprovar, por um lado, a incapacidade de imprimir eficiência na administração dos recursos públicos ou, por outro, a indisposição para democratizar o acesso aos serviços urbanos.

A erosão da legitimidade das políticas urbanas pode fundar-se, assim, na insuficiente adesão à racionalidade econômica, causa suposta do desperdício da base de recursos ou, alternativamente, na ausência de priorização de mecanismos distributivos do acesso a tais serviço. O impacto material das políticas será, conseqüentemente, contestado, seja pelo ângulo do desperdício de meios, seja pelo da concentração socioterritorial dos benefícios.

Mas a desigualdade social no acesso aos serviços urbanos é evocada para questionar a legitimidade das políticas urbanas igualmente nas chamadas "cidades imateriais", que estariam aparentemente ao abrigo de pressões indesejáveis sobre os fluxos de matéria e energia. Os espaços desindustrializados e deslocalizados pelo capital, afirma Beaucire (s.d., p.196), também terminariam por ser esvaziados em sua "urbanidade", fazendo que "a desqualificação social e a desqualificação ambiental progridam juntas, fazendo renascer o que se acreditava definitivamente superado, a insalubridade física e uma forma de gueto econômico e cultural no seio das cidades que são, entretanto, penetradas por redes técnicas com desempenho crescente". Acredita-se que "a alocação social e espacial dos custos engendrados pelas crises do desenvolvimento insustentável da cidade desdensificada será de realização delicada, a questão do desenvolvimento sustentável urbano correndo o risco de ser antes de tudo uma questão social" (idem, p.200).

A crise de legitimidade das políticas urbanas poderá ser atribuída também à incapacidade de se fazer frente aos riscos tecnológicos e naturais. Na perspectiva da eqüidade, o risco culturalmente construído apontará a desigualdade intertemporal no acesso aos serviços urbanos, com a prevalência de riscos técnicos para as populações menos atendidas pelos benefícios dos investimentos públicos ou afetada pela imperícia técnica na desconsideração de especificidades do meio físico das cidades tais como declividades, acidentes topográficos, sistemas naturais de drenagem, movimentações indevidas de terra, renovação de solo superficial, formação de voçorocas, erosão e assoreamento (Silva, s.d., p.72-91).

\section{CONCLUSÃO}

Se para Isabelle Stengers o conceito traduz o poder do intelecto de atingir o ser das coisas (Stengers \& Schlanger, 1988, p.24-7), ele tem também o poder de objetivar representaçōes, fazendo valer como legítimos, no real concreto, os esquemas ordenadores e classificatórios da construção intelectual. A enunciação conceitual é, portanto, também produtora de ordenamento, divisão e classificação no interior do mundo social. 
"As percepções do social", lembra-nos Chartier, "não são discursos neutros". Produzem estratégias e práticas que tendem a impor uma autoridade à custa de outras, a legitimar projetos reformadores ou a justificar, para os próprios indivíduos, as suas escolhas e condutas (Chartier, 1990, p.17). Conseqüentemente, "os esquemas geradores das classificaçōes e das percepçōes, próprios de cada grupo ou meio, são verdadeiras instituições sociais que incorporam sob a forma de categorias mentais e de representaçóes coletivas as demarcaçōes da própria organização social" (idem, p.18).

Associar a noção de "sustentabilidade" à idéia de que existe uma forma social durável de apropriação e uso do meio ambiente dada pela própria natureza das formaçōes biofísicas significa ignorar a diversidade de formas sociais de duração dos elementos da base material do desenvolvimento.

Colocar o debate sobre sustentabilidade fora dos marcos do determinismo ecológico implica, portanto, afastar representaçôes indiferenciadoras do espaço e do meio ambiente, requer que se questione a idéia de que o espaço e os recursos ambientais possam ter um único modo sustentável de uso, inscrito na própria natureza do território. A perspectiva não determinística, portanto, pressupóe que se diferencie socialmente a temporalidade dos elementos da base material do desenvolvimento. Ou seja, que se reconheça que há várias maneiras de as coisas durarem, sejam elas ecossistemas, recursos naturais ou cidades. ${ }^{14}$

As diferentes representações sobre o que seja a sustentabilidade urbana têm apontado para a reprodução adaptativa das estruturas urbanas com foco alternativamente colocado no reajustamento da base técnica das cidades, nos princípios que fundam a cidadania das populações urbanas ou na redefinição das bases de legitimidade das políticas urbanas (ver Quadro 1). A representação que privilegia a leitura da cidade como matriz tecno-material propõe a recomposição das cidades com base em modelos de eficiência ecoenergética ou de equilíbrio metabólico aplicados à materialidade do urbano. A redução da durabilidade da cidade à sua dimensão estritamente material tende a descaracterizar a dimensão política do espaço urbano, desconsiderando a complexidade da trama social responsável tanto pela reprodução como pela inovação na temporalidade histórica das cidades.

Quadro 1 - Matrizes discursivas da sustentabilidade urbana

1 Representação tecno-material da cidade

1.1. Modelo da racionalidade ecoenergética

1.2. Modelo do equilíbrio metabólico

\section{A cidade como espaço da "qualidade de vida"}

2.1. Modelo da pureza

2.2. Modelo da cidadania

2.3. Modelo do patrimônio

\section{A reconstituição da legitimidade das políticas urbanas}

3.1. Modelo da eficiência

3.2. Modelo da eqüidade

As propostas de reprodução adaptativa das estruturas urbanas que têm como referência a noção de qualidade de vida, estruturam-se segundo o modelo da pureza, da cidadania ou do patrimônio. A cidade é vista assim como espaço das externalidades negativas cujo equacionamento se dará na temporalidade do processo de construção de direitos,

14 "O que chamamos de duração é o envelope de todas as temporalidades possíveis. Convém que o de senvolvimento seja durável para que o homem ele mesmo possa durar na diversidade de suas culturas. A cidade, enquanto lugar da cidadania, é hoje o lugar da enunciação da responsabiliade de cada um com respeito a todos"; cf. Micoud, A., "L'Écologie Urbaine Nouvelles Scènes d'Énonciation", in Écologie et Politique, Paris, n.7, p.42, été 1996. 
Henri Acselrad é economista, doutor em Economia pela Universidade de Paris I e professor do IPPUR/UFRJ. E-mail: acsel@ibm.net

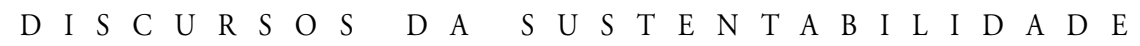

sejam direitos ao que serão consideradas condições saudáveis de existência, sejam direitos ao usufruto durável da existência simbólica de sítios urbanos. A palavra cidadania retorna assim a seu espaço de origem - a cidade -, sobrepondo-se ao sentido até aqui dominante, referido ao Estado-Nação.

As propostas de reprodução adaptativa das estruturas urbanas, que têm por foco o reajustamento das bases de legitimidade das políticas urbanas, procuram, por sua vez, refundar o projeto urbano segundo o modelo da eficiência ou da eqüidade. Em ambos os casos, estará em jogo a cidade como espaço de construção durável de pactos políticos capazes de reproduzir no tempo as condiçôes de sua legitimidade. Ao promover uma articulação "ambiental" do urbano, o discurso da sustentabilidade das cidades atualiza o embate entre "tecnificação" e politização do espaço, incorporando, desta feita, ante a consideração da temporalidade das práticas urbanas, o confronto entre representaçóes tecnicistas e politizadoras do tempo, no interior do qual podem conviver, ao mesmo tempo, projetos voltados à simples reprodução das estruturas existentes ou a estratégias que cultivem na cidade o espaço por excelência da invenção de direitos e inovações sociais.

\section{REFERÊNCIAS BIBLIOGRÁFICAS}

ACSELRAD, H. Sustainability and Territory. In: Internacional Seminar on "Sustainability as a Concept for Social Sciences". Frankfurt: ISOE/Unesco, 1996.

ALVA, E. N. et al. Metrópoles (in)sustentáveis. Rio de Janeiro: Relume Dumará, 1997.

BLOWERS, A. (Ed.). Planning for a Sustainable Environment. Londres: Earthscan, 1996. BOURDIEU, P. O poder simbólico. Rio de Janeiro/Lisboa: Difel/Bertrand, 1989.

BREHENY, M., ROOKWOOD, R. "Planning the Sustainable City Region". In: BLOWERS, A. (Ed.). Planning for a Sustainable Environment. Londres: Earthscan, 1996. p.151.

BRUNDTLAND, G. Nosso futuro comum. São Paulo: Editora Fundação Getúlio Vargas, 1987.

CAMAGNI, R., GIBELLI, M. C. Développement Urbain Durable - Quatre Métropoles Européennes. Paris: DATAR-L'Aube, 1997.

CARRIZOSA, J. "The Evolution of the Debate on Sustainable Development". In: Workshop Internacional "Definindo uma Agenda de Pesquisas Sobre Desenvolvimento Sustentável”. Anais... Rio de Janeiro: FGV, 1994. (Mimeo.)

CHARTIER, R. A história cultural - entre práticas e representações. Rio de Janeiro: Difel, 1990.

COSTA, A. C. R. da. "Da economia da beleza à beleza da economia". Rio de Janeiro: IPPUR, 1997. (Mimeo.)

COSTA, J. F. A ética e o espelho da cultura. Rio de Janeiro: Rocco, 1994.

DALY, H. (Ed.). Economia, Ecologia, Ética - ensayos hacia una economia en estado estacionario. México: Fondo de Cultura Económica, 1979.

"From Empty-World Economics to Full World Economics: Recognizing an Historical Turning Point in Economic Development". In: GOODLAND, R., DALY, H., EL SERAFY, S. (Eds.). Environmentally Sustainable Economic Development: Building on Brundtland. Washington: The World Bank, 1991.

DÉLÉAGE, J. P. "L’Avenir des Villes". Écologie et Politique, Paris, n.13, p.13-6, printemps 1995. 
DURAZO, E. P. "Desarrollo sustentable de las ciudades". Ciudades, México, n.34, p.51, abr.-jun. 1997.

EL SERAFY, S. “The Environment as Capital”. In: CONSTANZA, R. (Ed.). Ecological Economics - The Science and Management of Sustainability. Columbia: Columbia University Press, 1991.

EMELIANOFF, C. "Les Villes Durables, l'émergence de nouvelles temporalités dans des vieux espaces urbains". Écologie et Politique, Paris, n.13, p.37-58, printemps 1995.

FABIANI, J. L. "Sciences des Ecosystèmes et Protection de la Nature". In: CADORET, A. (Ed.). Protection de la Nature. Histoire et Idéologie. Paris: Ed. L'Harmattan, 1985. p.75-93.

GODARD, O. "Environnement, Modes de Coordination et Sistèmes de Legitimité: Analyse de la Categorie de Patrimoine Naturel". Révue Economique, Paris, n.2, p.215-42, mars 1990.

. "Le Développement Durable et le Dévenir des Villes, Bonnes Intentions et Fausses Bonnes Idées". Futuribles, Paris, p.29-35, mai 1996.

HARVEY, D. A condição pós-moderna. São Paulo: Loyola, 1992.

MICOUD, A. "L'Écologie Urbaine - Nouvelles Scènes d'Énonciation". Écologie et Politique, Paris, n.7, p.31-44, été 1996.

OMISHI, T. "A Capacity Approach for Sustainable Urban Development: an Empirical Study”. Regional Studies, v.28.1, p.39-51, 1993.

PASSET, R., THEYS, J. (Eds.). Héritiers du Futur - Aménagement du Territoire, Environnement et Développement Durable. Paris: Ed. de L'Aube, 1995.

PCDF - People Centered Development Forum. "Sustainability as the Organization Principle of People-Centered Development”. Nova York: s.n., 1992. (Mimeo.)

POUGH, C. (Ed.). Sustainability, the Environment and Urbanization. Londres: Earthscan, 1996.

SAHLINS, M. Cultura e razão prática. Rio de Janeiro: Zahar, 1979.

SHIVA, V. "Que quiere decir sustentable". Revista del Sur, Montevideo, n.3, marzo-abril, 1991.

SILVA, L. O. "A ocupação do espaço construído e qualidade ambiental: o caso da cidade de SP”. In: __. Ambiente Urbano e Qualidade de Vida. São Paulo: Polis, s.d. p.72-91.

STENGERS, I., SCHLANGER, J. (Eds.). Les Concepts Scientifiques, Invention et Pouvoir. Paris: La Découverte, 1988.

WORSTER, D. The Illusionary Promise of Sustainable Development. Kansas: University of Kansas, s.d. (Mimeo.)

A B S T R A C T The idea of sustainability recalls the logic of practice, where practical effects viewed as desirable are made to happen, rather than the field of scientific knowledge, where concepts are constructed to explain reality. When applied to urban space, the idea of sustainability has generated different representations and perspectives for managing cities, from the administration of risks and uncertainties to the increase of "resilience" - the adaptive capacity - of urban structures. What seems to organize analytically the discourse of "urban sustainability" is its division into two fields: on the one hand privileging a technical representation of cities by combining the notion of urban sustainability with the "modes of management of the flows of energy and materials associated with urban growth"; on the other hand defining the unsustainability of cities by the drop in productivity of urban investments, that is, by 


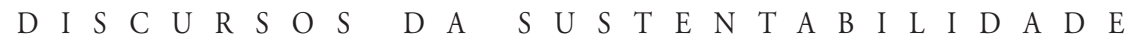

the "incapacity of the latter to keep up with the rate of growth of social demands", which consequently places urban space in jeopardy as a political territory.

KEYW ORDS Sustainability; urban planning; environmental politics. 